\title{
Assessing Transfer from Track Two Diplomacy: The Cases of Water and Jerusalem*
}

\author{
ESRA CUHADAR \\ Department of Political Science, Bilkent University
}

\begin{abstract}
This article focuses on the evaluation of transfer from Track Two diplomacy to negotiations and policymaking by examining four Track Two initiatives between Israelis and Palestinians over the issues of water and Jerusalem. The article first discusses the transfer process for the water and Jerusalem cases and then presents lessons drawn from the comparative study. The comparative assessment reveals similarities concerning transfer in terms of what the contributions of Track Two are to the process of negotiations, which transfer strategies are used, and what conditions are necessary to make a contribution to the outcome. Initiatives in both cases employ primarily the strategy of working with influential people and they are more successful in impacting the process of negotiations rather than the outcome. Their contribution to the process of negotiations shows regularities in the types of learning acquired and used. Successful transfer to outcome is observed in one occasion when transfer strategies were implemented effectively, the negotiators were open to outside information, and there was political willingness. Asymmetrical transfer of people, and of ideas, from Track Two initiatives to negotiations was a barrier to effective transfer.
\end{abstract}

\section{Introduction}

Track Two diplomacy has increasingly been recognized as a third-party intervention method to deal with intractable conflicts because of its ambition to address the underlying causes of conflicts and its aim to improve relations between the adversaries. In this article, the term Track Two diplomacy is used to refer to a variety of nongovernmental and unofficial forms of conflict resolution activities between the representatives of adversarial groups that aim at de-escalating conflict, improving communication and

\footnotetext{
* esracg@bilkent.edu.tr. The author is grateful to the Moynihan Institute for Global Affairs and the Program on the Analysis and Resolution of Conflicts at Syracuse University for research funding and would like to thank Jim Bennett, Bruce Dayton, Tamra d'Estree, Peg Hermann, Lou Kriesberg, Brian Mandell, Chris Mitchell, Robert Rubinstein, and the anonymous referees for their comments.
}

understanding between the parties, and developing new ideas to be used in the official peace processes (Montville, 1995).

The range of goals and practices in Track Two diplomacy vary. Yet, two main assumptions appear as common denominators of Track Two initiatives. The first is the underlying belief that contact and interactions between the members of adversarial groups in an unofficial and friendly setting, often with the help of a third party, help improve relations and generate a joint understanding of the conflict. The second assumption is that the improved relations and jointly formulated ideas are transferred and incorporated into the society and/or the official policymaking processes, thus, having an impact at a larger scale.

Although the number of Track Two workshops increased in the last couple of decades, the effectiveness of these efforts based on the 
above-mentioned assumptions has hardly been evaluated, except in individual accounts recorded by practitioners. Scholars like d'Estree et al. (2001), Fisher (1997), and Rouhana (2000) called attention to the evaluation of problem-solving workshops as a necessity in order to improve and increase the credibility of the practice. Rouhana (2000) suggested that evaluation of problemsolving workshops should be undertaken at two different levels: (1) evaluation of the micro-objectives (the impact of the workshop activities on the immediate participants), and (2) evaluation of the macro-goals (the impact of workshops on the conflict dynamics at large).

This study addresses the second level by focusing on the evaluation of transfer from Track Two diplomacy to the macro level and elaborates how this process has worked in four Israeli-Palestinian problem-solving workshops that are examined. The article first overviews the existing literature on transfer, then reports the transfer process in the water and Jerusalem cases, and finally presents some lessons drawn from the comparative case study of the four Track Two initiatives.

While the water conflict is about sharing the scarce water resources in the region without jeopardizing the quality of these resources, the Jerusalem conflict is about sovereignty over the city and surroundings. In each of the two issue areas, two Track Two initiatives are examined.

The two initiatives concerning water were carried out by the Israel/Palestine Center for Research and Information (IPCRI initiative) and by the Truman Institute and Palestine Consultancy Group (Truman-PCG initiative). The initiatives on Jerusalem were undertaken by the Economic Cooperation Foundation and the Arab Studies Society (ECF-ASS initiative) and by the Jerusalem Institute for Israel Studies and the International Peace and Cooperation Center (JI-IPCC initiative). All of these initiatives took place at the pre-negotiation stage (before the Oslo II and/ or the final status negotiations) and involved mid-to-high-level participants. Although the two issues seem to be very different in nature one extremely politically charged, the other relatively more technical - an important finding of the comparative analysis is that in terms of transfer effects and outcomes, strategies of transfer, and indeed for the most part success in transfer, the Track Two initiatives have been remarkably similar.

\section{Evaluation of Track Two Diplomacy and Transfer}

In recent studies evaluating micro-objectives, Maoz (2000), Ohanyan \& Lewis (2005), and Malhotra \& Liyanage (2005) evaluated workshops with youth to assess whether contact between the members of adversarial groups resulted in improved relations in the short or long term. Despite the increase in the number of evaluations focusing on the micro-objectives, systematic research is still lacking especially on the evaluation of micro-objectives in workshops held with elites and policymakers, and on the evaluation of the link between the micro-objectives and the macro-goals, known as the transfer effects of the workshops.

The early practitioners of Track Two diplomacy assumed that the innovative analysis of conflicts and positive changes in the attitudes in the Track Two meetings later on transfer to the official policymaking automatically. However, this idea was simplistic and inadequate to help understand the processes that take place in and between the micro and the macro levels.

Several attempts have been undertaken by Fisher (1997), Kelman (1995), and Mitchell (1981, 1993) to elaborate the simple intuition of early practitioners about transfer. Fisher (1997: 202-204) has suggested that the closer the Track Two participants are to the decisionmakers, the more likely it is that transfer to Track One will be direct; the more 
distant they are from the decisionmakers, the more likely it is that transfer will be indirect.

Mitchell (1981) and Kelman (1995) emphasized the trade-off between engaging participants closely connected to the decisionmakers and those that are not. They have argued that the closer the participants are to the decisionmakers, the more likely it is that they will be politically conformist and resistant to change. The further away they are from official circles, the more likely that they will be flexible. Mitchell, in addition, suggested that the closer and more conformist they are, the more likely it is that transfer will be direct; and the further and more flexible they are, the more innovative their recommendations will be, but the less likely that there will be direct transfer to Track One.

Recent studies by d'Estree et al. (2001) suggested indicators to assess Track Two diplomacy at three levels: the micro level (relational and cognitive changes), the link between the micro level and the macro level (foundations for transfer), and the macro level (foundations for outcome). Yet, these indicators were not tested empirically and were not specified for activities that take place at a specific stage of a conflict with a certain level of people. Overall, attempts so far to elaborate the simple intuition about Track Two remained inadequate in accounting for the complexities of the processes that take place at both the micro and the macro levels, and between these two levels, and have hardly been evaluated against empirical data.

Transfer is usually defined as 'how effects (e.g. attitudinal changes, new realizations) and outcomes (e.g. frameworks for negotiation) are moved from the unofficial interventions to the official domain of decision and policy making' (Fisher, 2005: 3). This article defines transfer in a similar manner but, for precision, adds three directions: upwards, downwards, and lateral. The traditional emphasis in the literature on the transfer of workshop effects and outcomes to the negotiations and official domain of decision and policymaking (Fisher, 2005; Kelman, 1995; Mitchell, 1981, 1993) is what will be referred to as upwards transfer in this article (for other types, see Cuhadar, 2004).

The findings discussed in this article concern upwards transfer. The research questions are posed specifically for pre-negotiation type Track Two initiatives that were undertaken with mid-to-high-level participants. Figure 1 shows the stage of conflict de-escalation and level of participants selected as the focus of this research. Depending on the location on this chart, the goals and methods articulated for micro- and macro-level changes are expected to vary as well. For example, the goals and methods, as well as the transfer strategies, used for workshops with semi-official people aiming at assisting official negotiations are different from workshops that gather university students from the grassroots level at the post-conflict peacebuilding stage.

\section{Method}

Structured-focused comparative case study method was used to systematically examine the four cases in this study (see George \& Bennett, 2005). The cases are described below.

Data were collected through 60 interviews carried out between 2002 and 2004 with the participants and organizers of the workshops, and with Israeli, Palestinian and American policymakers and negotiators involved in water and Jerusalem issues. Two separate interview protocols were designed: one for the participants and organizers and the other for the negotiators and policymakers. The protocol for the participants included questions in four categories: relations with the others, types of learning in the workshops, transfer strategies, and the implementation of the transfer strategies. The population of participants interviewed for each initiative was determined with the help of organizers and snowball sampling. Interviews were 
Figure 1. Stages and Levels of Participants*

Types of participants, degree of officiality

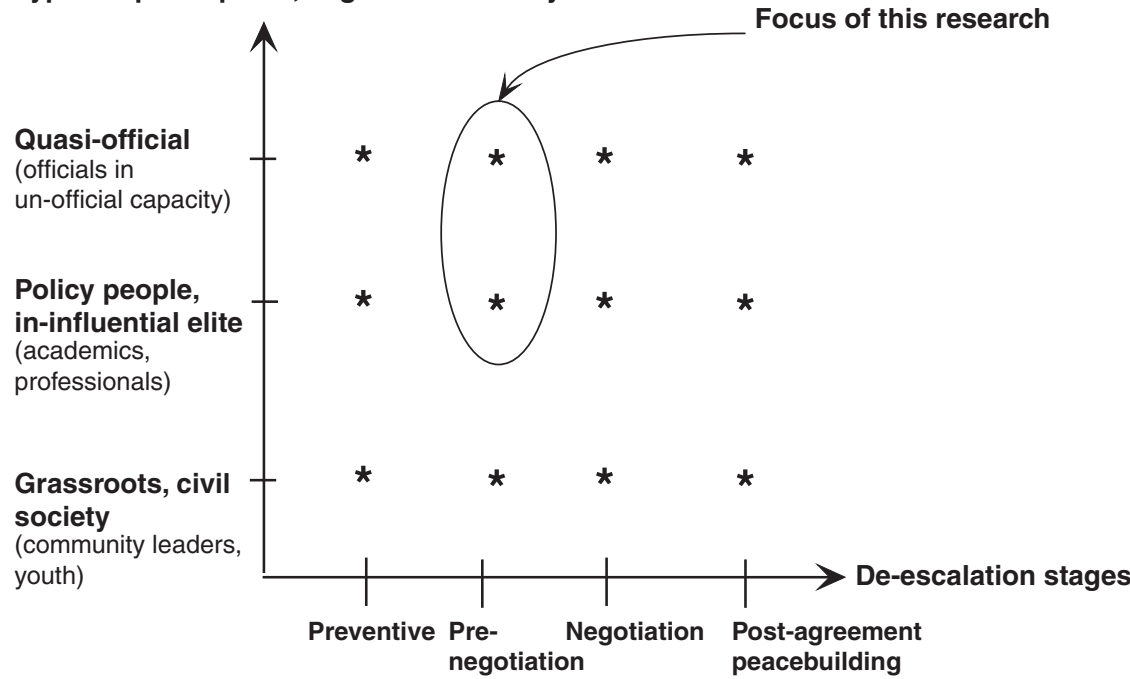

* This figure builds on levels of peacebuilding in Lederach (1997: 39).

carried out with $80-90 \%$ of the core group members for the two water initiatives and at least $70 \%$ of the core group members for the Jerusalem initiatives.

The second protocol aimed at understanding the level of information and involvement of the policymakers and negotiators in the concerned Track Two initiatives and asking about the implementation of the transfer strategies. The policymakers and negotiators interviewed on the Palestinian and Israeli sides were from institutions such as the Israeli Water Commissioner's Office, Joint Water Committee, and members of the negotiation teams.

When available, documentary data such as meeting minutes, joint statements, annual reports, and published interviews with participants were also used.

The data were coded for content with the help of a software program. The content analysis used a combination of deductive and inductive coding. For the deductive part, a codebook was created based on the themes suggested in the literature, especially based on d'Estree et al. (2001). Data concerning these categories were coded following this codebook and the frequency of each theme in each interview was reported. ${ }^{1}$

\section{Cases}

All Track Two cases were selected according to the theoretical focus of this research as shown in Figure 1. The initiatives aimed at producing jointly formulated outcomes to be publicized and to assist the negotiations, as well as trying to build relationships among their participants as a by-product. In this structured-focused comparative case study, the initiatives selected were controlled for the following variables: (1) time frame in which the initiatives took place (between 1991 and 2000); (2) number of parties in the conflict (bilateral issues that included only Israelis and Palestinians); (3) stage of the conflict (before and in-between the negotiations); (4) level of participants (all were undertaken

${ }^{1}$ Tables on frequency distributions are available in Cuhadar (2004). This article reports only general tendencies. 
with professional people); (5) duration of the initiatives (all lasted for at least three years); and (6) format of the process followed. They were all policy-oriented problem-solving workshops attended by issue experts and politically connected people. This was the case not only for water workshops, but also for Jerusalem workshops which included experts on religious affairs, city planners, lawyers, etc. On the other hand, the Track Two initiatives examined varied in terms of the nature of the dispute (water vs. Jerusalem).

The IPCRI water initiative was founded in the early 1990s with the aim of providing a forum for Israeli and Palestinian water experts to engage in problem-solving and to help them explore ideas, options, and solutions that would meet the interests of both parties.

IPCRI created two parallel projects on water. The first was round tables between Israeli and Palestinian water professionals. The goal of the meetings was to get water experts from both sides of the conflict acquainted with each other, engage them in a dialogue over water issues, and explore each other's positions and interests. The number of participants changed from one meeting to another, but the size of the group grew in time from single digits in the early 1990s to more than 20 in the mid-1990s. The meetings continued regularly until the late 1990s.

The parallel project to the round tables, which took place with the participation of four of the veteran round-table participants, was a small Israeli-Palestinian working group. The group included a Palestinian and an Israeli academic, an Israeli water consultant, and a Palestinian water expert. These group members met frequently in order to formulate a regional water master plan that could form the basis for some policy recommendations (see Assaf et al., 1993, for more information).

The Truman-PCG initiative targeted one of the thorniest issues in the water conflict: the situation of the shared Mountain Aquifer, a main source of fresh water for both Israelis and Palestinians. The aim of the initiative was to conduct policyoriented dialogue on the management of the aquifer in order to contribute to the final status negotiations. The initiative brought together a group of influential policy people working on water, as well as academics and hydrologists from both sides. The initiative was funded by the International Development and Research Center and the CRB Foundation and took place between 1994 and 2002. Throughout this time, most of the group participants remained the same (see Feitelson \& Haddad, 1995, 2000, for more information).

The ECF-ASS initiatives dealt mostly with the functional-technical, but also with the political aspects of the Jerusalem issue. ECF began working on final status issues after the signing of the Oslo agreements and within the framework of the Beilin-Abu Mazen backchannel talks. With these general political frameworks in the background, ECF began focusing on the Jerusalem question and started to work with ASS under Faisal Husseini's leadership. The goal was to bring expertise into the dialogue, to explore new ideas and discuss their feasibility, and to disseminate these ideas to the decisionmakers. An additional goal on the Palestinian side was to prepare the Palestinians for the negotiations by building their capacity.

The ECF-ASS initiative on Jerusalem continued in three tracks with some overlapping people in each. 'Planning Jerusalem in Peace', which focused on the municipal aspects of the conflict, was carried out with a group of about eight people from each side, consisting of professionals and experts on the city. The later initiatives were the London and Italian tracks, which focused on legal and political issues such as sovereignty and were held in the round-table format with a mixed group of professionals and politicians. 
The JI initiated Israeli-Palestinian workshops with professionals in 1995, first with the ASS. After 1998, these joint activities continued with a new Palestinian NGO called IPCC. The joint activities of JI and IPCC were funded by the Olaf Palme Institute until 2000, with the goal of conducting policy-oriented dialogue between professionals and experts on Jerusalem. Among these professionals were urban planners, economists, lawyers, diplomats, and sociologists. The initiative adopted a functionalist approach focusing on the technical and municipal problems of Jerusalem that required cooperation, rather than the political aspects. The goal of the initiative was to produce and promote ideas that would 'improve the quality of life in the city for both parties' (Jerusalem Institute for Israel Studies, 2002: 28-29).

Within the framework of this initiative, a workshop was held in Sweden each year with the larger group for about five days. The group consisted of approximately eight professionals on each side. In between these workshops, smaller working groups of Palestinian and Israeli professionals continued their work.

\section{Outcomes of the Transfer Process}

Transfer outcomes in the upwards direction should be viewed in two categories: transfer from Track Two initiatives to the official process and to the outcome. While the former means that the effects and outcomes generated in the initiatives made a contribution to the process of decisionmaking and negotiations, the latter refers to situations in which the Track Two initiatives managed to contribute to the negotiation outcome. This section discusses transfer in these two categories for Jerusalem and water cases separately and the next section presents a comparative analysis.

\section{Transfer from Track Two in Jerusalem}

For Jerusalem, both Track Two initiatives came up with innovative ideas and insights.
For instance, the JI-IPCC project generated insights as to how urban life (e.g. improving the urban economy, management of cultural and religious sites, municipal borders) in Jerusalem can be improved in a shared city. The ECF-ASS initiative promoted ideas related to different types of sovereignty and their practical implementation, and about how to maintain Jerusalem as an 'open city'.

The contributions of Track Two initiatives to the negotiations in the case of Jerusalem were limited to the process of negotiations. These contributions began during the preparation for the Camp David talks, despite important barriers to effectiveness, but intensified and improved as the negotiations evolved between Camp David in summer 2000 and Taba in January 2001. A key contribution to the process was when detailed maps and data generated in the Jerusalem initiatives were used by the policymakers and negotiators on both sides, especially during the talks between Camp David and Taba when the two sides delved into the details of the Jerusalem issue. Until after Camp David, however, owing to political unwillingness from both sides' leaderships, existence of competing Track Two channels, and asymmetrical transfer of people and ideas, contributions to the process could not become effective and did not have much input into the political process.

During the preparation phase, on the Israeli side Prime Minister Ehud Barak refused to deal with Jerusalem officially until the negotiations began. He did not authorize his negotiators to prepare materials and policy papers that could be used for the negotiations. Track Two initiatives filled this vacuum, both before and during the Camp David negotiations, through transfer of maps and policy papers from the JI and the ECF to Israeli negotiators Oded Eran, Gilead Sher, and Shlomo Ben Ami, and also to the US peace team. The JI conveyed their understanding about what they thought was the 'backbone of the Palestinian line', in meetings especially with Oded Eran, but they did not 
necessarily present an integrative outcome that is jointly agreed upon in Track Two meetings. All the options presented by the JI were based on a physically undivided city (Klein, 2003: 52). The second option that the JI highlighted was similar to the Israeli offer made in the Camp David negotiations, which emphasized functional autonomy for Palestinians under Israeli sovereignty, limited exchange of territory at the edges of the city, symbolic official presence for Palestinians in Jerusalem, special status in the Old City, and continuation of the status quo in the Haram/Temple Mount (Klein, 2003: 52).

On the Palestinian side too, within the existing lack of political willingness, Track Two initiatives filled a vacuum. Maps, data, and policy papers concerning the urban and municipal issues became important contributions. A Palestinian participant of the ECFASS initiatives who served in the negotiation team argued:

We got information that we didn't have, like detailed maps on Jerusalem and settlements, through the second track. We learned what was happening on the ground, statistics, etc. ... For me, it was a great benefit at Camp David because Clinton and even the Israeli politicians recognized that technically we were well prepared. We had materials ready for everything they talked about .... This is the accumulation that came through the second track.

Despite the well-prepared technical people in the negotiations, the input by Track Two could not become sufficiently effective, owing to political problems. The lack of effectiveness in benefiting from the Track Two initiatives was mentioned by people from the Palestinian Negotiation Support Unit (NSU), under the Negotiation Affairs Department (NAD), and also by Palestinian Track Two participants such as the following:

I was frustrated with the Palestinian system. I didn't feel that there was enough dissemination of information on our side where one address would work and you would bring the results to that address.
During this stage, one barrier to the effective transfer of ideas and proposals from the Track Two initiatives was competing political channels. For example, Faisal Husseini from the ASS, who held the PLO's Jerusalem portfolio, initially played an active role in the preparatory talks held between Yaser Abed Rabbo/Saeb Erakat and Oded Eran. He appointed a team from the Orient House to do preparatory work for negotiating about Jerusalem (Klein, 2003: 50). The team included people who attended the Track Two initiatives with the JI and ECF through ASS. However, these talks were running parallel to other back-channel talks between Abu Ala and Shlomo Ben Ami/Gilead Sher (Ross, 2004: 603). Palestinian negotiators, other than Arafat, initially were not aware of the existence of another channel with Israelis. Although the Rabbo-Erakat and Oded Eran channel was open to the transfer of the work done in the ASS Track Two, it was in the parallel back-channel that Jerusalem was brought up and discussed in May 2000 (Ross, 2004). Yet, this channel did not involve Husseini or the professional group at the ASS, or anyone from the NAD, which was the national-level Palestinian organization headed by Abu Mazen doing preparatory work on final status issues, including Jerusalem. The barrier of competing channels was mentioned by a Palestinian member of the NSU as follows:

$\mathrm{X}$ individual was negotiating with $\mathrm{Y}$ and had clever ideas but hadn't shared it with anybody else. So, when there was some opportunity for direct negotiation on the matter, there was nobody to carry out the information forward because this person had not shared it and because this person was expecting to be in the negotiations. The talks had to have him .... But often somebody was left out. So, the information flow did not take place.

Therefore, because of competing channels and lack of access of key influential people to all channels, Track Two effects and outcomes were not transferred to the Palestinian negotiators effectively at the preparatory stage and 
during the Camp David talks. Still, maps and data found their way to the technical people, although in a non-systematic manner.

Maps and data were also the kind of input that was sought by the negotiators and by the US peace team at Camp David, as the head of the team Dennis Ross articulated:

So much of what was being discussed on Jerusalem got into the nitty gritty of life there: How you would handle municipal powers, how you would deal with the daily life of the city, how you would create equal access to all religious sites. So, I was aware [of the initiatives] and generally would read their accounts. They were providing raw material, data on what life is really like neighborhood by neighborhood, which was something that we had to contend with. That was not really available to us. So, what they were doing provided it.

During the Camp David summit, the discussion on Jerusalem never got to a detailed level (Ross, 2004: 657). It reached this level only during the negotiations following Camp David. Still, towards the end of the summit, the US peace team brought to the table several ideas related to sovereignty over the Old City and Jerusalem as they were fed constantly by the ECF. Another member of the US peace team mentions:

I was hoping that they [ideas/proposals from Track Two initiatives] would be more useful than they ended up being. We tried them out in Camp David. We were hoping that both sides would accept them. Ended up that we were not able to forge a compromise based on those ideas.

Neither the ideas sent through the faxes nor the transfer of key Israeli people from the Track Two meetings to the negotiations was effective in bridging the differences and influencing the negotiation outcome. The proposals coming from the organizers of the Track Two initiatives did not always reflect a jointly agreed upon and complete understanding that could bridge the gap between the Israeli and Palestinian positions. Neither did they provide proposals complementing those suggested for other connected issues such as security, borders, and settlements. ${ }^{2}$

Furthermore, the transfer of people and proposals from Track Two meetings to the official negotiations was asymmetrical during the Camp David summit. The Israeli organizers of the Track Two initiatives were more directly connected to the negotiators than their Palestinian counterparts. While there were people affiliated with the $\mathrm{JI}$ and the ECF at the negotiations, this was not the case for the Palestinian side, especially after Faisal Husseini was left out. In addition, Barak and Arafat refrained from authorizing their negotiators on the issue of Jerusalem (Ross, 2004; Malley \& Agha, 2001). Thus, there was not sufficient closeness or direct links to the decisionmakers.

After the Camp David summit, until the announcement of the Clinton parameters in December and Taba negotiations in January, interactions between Track Two people and officials became more systematic, frequent, and institutionalized. For example, an advisory 'peace team' was established at the Israeli Prime Minister's office which included people who were involved in the ECF and JI initiatives. These people had direct exchange with negotiator Gilead Sher and continued to provide information, maps, and solutions concerning Jerusalem until the Taba negotiations.

On the Palestinian side too, during this period, Track Two participants had more access to their negotiators. After the summit, Palestinian officials became more open to Track Two and coordination between the Ministry of Planning and International Cooperation, Orient House, and NSU improved. For example, one of the ideas - land swaps for East Jerusalem settlements - that was first suggested in an ECF-ASS meeting was taken by the Palestinian negotiators and passed

${ }^{2}$ Interview with assistant to Gilead Sher, Tel Aviv, September 2003. 
back onto Track Two for further exploration. ${ }^{3}$ This idea was accepted by both sides in the Taba negotiations (Cingoli, 2001; Hassassian, 2001 on land swaps).

Yet, during this time, the focus continued to be primarily on functional and municipal matters. The negotiators made progress on these issues and discussed them in a detailed manner, as recommended by the Track Two initiatives. However, the religious aspects of Jerusalem remained the core of the problem and yet very few concrete ideas were offered in the Track Two initiatives on these, with the exception of the establishment of a Jerusalem Religious Council to supervise all the religious matters (Cingoli, 2001: 12; Hassassian, 2001).

In short, the contributions of Track Two to negotiations were limited to input into the negotiation process only, mostly on the functional aspects of the Jerusalem question. The initiatives involved influential people who had direct access to negotiations and to negotiators. However, such direct links and the ideas proposed were not adequate to reconcile the differences between the parties.

\section{Transfer from Track Two in Water}

Many innovative ideas and insights were also generated in Track Two meetings on water. For example, IPCRI meetings elaborated upon the 'minimum water requirement' and drafted a 'regional water master plan' (Assaf et al., 1993). Likewise the Truman-PCG project came up with various types of joint management structures for the shared aquifers that would meet both Israeli and Palestinian needs (Feitelson \& Haddad, 1995, 2000). While transfer of ideas and insights was limited to only the process in the Jerusalem case, in the water case there was transfer to both process and outcome. The Truman-PCG initiative's work on the joint management

${ }^{3}$ Interview with a Palestinian negotiator, Ramallah, September 2003. of shared aquifers inspired the related article in the 1995 Oslo agreement and the operationalization of the Joint Water Committee (JWC), a by-product of that agreement.

The transfer to outcome occurred, in this case, because the idea of joint management was advocated symmetrically in the negotiations by both sides, even though the connection to the negotiations on the Palestinian side was more direct than on the Israeli side. However, this outcome was achieved not only because the idea of joint management was transferred symmetrically by key participants, but also because of openness to information and of political willingness within the Palestinian and Israeli negotiation teams.

The members of the official negotiation teams who were affiliated with the TrumanPCG initiative were all water experts and technical people. There were more direct mechanisms of transfer on the Palestinian side because two of the Palestinians from the initiative were in the negotiation team. Israeli members of the initiative did not directly take part in the official negotiations, but the initiative had included an influential Israeli water expert, who was an ex-deputy water commissioner, with close contacts within the Israeli negotiation team and water establishment. The initiative also had contacts with one of the Israeli technical experts, Uri Shamir, in the negotiation team. So, the Israeli members of the initiative had access to the negotiators via intermediaries. Shamir was well informed about the initiative outcomes and was in favor of the idea of joint management, saying: 'since water knows no boundaries, joint management makes good sense and is probably inevitable' (Rouyer, 2000: 195).

The internal dynamics of the negotiations in terms of openness to information within the Israeli team and political willingness were at least as important as the efforts of the TrumanPCG participants in this transfer to outcome. Israeli position on the issue of joint management and water rights evolved between the 
1994 Cairo and 1995 Oslo II negotiations. ${ }^{4}$ It was also due to the increasing influence of Shimon Peres, then Foreign Minister, and his group on bilateral water negotiations and their more accommodating position towards the acceptance of the Palestinian water rights and joint management of shared water resources (Rodan, 1995; Rouyer, 2000).

Within the Labor government there were different attitudes towards the water issue between the security-defense group close to Rabin and the foreign affairs group led by Peres. ${ }^{5}$ The former tended to see water as a national security matter and preferred exclusive control by Israel of the shared resources, while the latter tended to regard water in more economic terms and as a basis for regional cooperation. The bilateral water negotiation team was headed by an appointee of Rabin, Noah Kinarti, known as a hardliner with close ties to the IDF, objecting to the joint management of shared resources and the recognition of Palestinian water rights. ${ }^{6}$

Just before the Oslo II negotiations, Kinarti's power in the negotiations diminished when he was replaced by Gideon Tsur, the Water Commissioner at that time, as the head of the Israeli water team. This strengthened the position of those in the negotiations who favored the idea of joint management. Tsur was a water professional advocating economically sound solutions to water conflict. Also, one of the water professionals that he appointed as the head of a water examination committee was Saul Arlosoroff, an influential Israeli participant of the TrumanPCG initiative. ${ }^{7}$ Soon after this change in

\footnotetext{
${ }^{4}$ About this change, see Savir (1998), Rouyer (2000), and Rodan (1995).

${ }^{5} \mathrm{I}$ use these terms for affiliations rather than official posts at these institutions.

${ }^{6}$ It was reported that Kinarti was 'willing to torpedo the talks over one drop of water' and he thought 'Jordanians and Palestinians would not get one drop of Israel's water' (Rodan, 1995).

${ }^{7}$ Gideon Tsur appointed the 'Committee for Examining the Management of the Supply of Water in Israel' in order to examine water pricing policies. See Knesset Report (2002).
}

the negotiation team, Tsur reached an agreement with Ahmed Qureia on water with the approval of both Peres and Rabin.

After the second Oslo negotiations, the contributions of the Truman-PCG initiative to the process continued, although in a diminished way, as one of the Palestinian participants took on a senior position as the head of the Palestinian technical committees at the JWC. The JWC, established with the Oslo II agreement, was a new governing structure designed to function as a joint decisionmaking body over the shared water resources of the West Bank. There were equal numbers of Israelis and Palestinians on each of the four subcommittees, and the decisions were to be made by consensus.

Yet, transfer of people to the JWC from the Truman-PCG project was asymmetrical, with no Israeli counterparts from the initiative serving at the JWC. Furthermore, this time the Israelis did not have a close contact within the JWC from the second track initiative. On the contrary, one of the technical advisers of Kinarti who was not in favor of the Truman-PCG initiative became the head of the technical subcommittees in the JWC as the counterpart of the Palestinian participant from the Truman-PCG. He participated in one of the workshops but did not become a permanent participant and criticized the initiative for not offering any practical idea to improve the water problem, although he did praise it for bringing the two sides together. ${ }^{8}$ Thus, although the Truman-PCG initiative was influential at the negotiation and outcome levels, it hardly affected the implementation of the agreement in this new political structure. The following statement by one of the Palestinian official negotiators from the Truman-PCG initiative illustrates the disappointment with the Committee:

\footnotetext{
${ }^{8}$ Interview with the concerned Israeli water official, Tel Aviv, 2002.
} 
If you read Oslo B there is kind of coordinated management and this was influenced by our work. The idea was taken from our work. They used it in their own way .... It is a joint management mechanism, but it is malpracticed. The Israelis were doing everything one sided. They often came to the Joint Water Committee and said approve it.

The consequence of the asymmetrical transfer of people to the JWC was negative. The functioning of this institution relied heavily on trust, even more than the negotiations. The institution in the beginning was seen as a success and first step towards joint management by the participants of the Truman-PCG initiative. In time, the functioning of the institution was hampered by the Israeli vetoes, and problems became common between the water commissioners and the members of the subcommittees (Lein, 2000: 33). Consequently, Palestinian members of the Truman-PCG initiative were frustrated to the degree that some of them began to question the feasibility of implementing joint management. Had there been symmetrical transfer of people and trust at the subcommittee levels of the JWC, perhaps there could have been better prospects for cooperation. In fact, a Palestinian member of the Truman-PCG initiative and the Palestinian head of the technical subcommittee of the JWC thought: 'If we continued to work with people like [a member of the Truman-PCG initiative] at the JWC too, the situation could have been better.'

As far as the IPCRI initiative is concerned, the inputs from the projects in the 1990s to the negotiations were in terms of process and were mainly through the transfer of professional people from the Track Two initiatives to the multilateral negotiations. Especially in the early 1990s, Palestinian participants had acquired data, technical skills, and new knowledge through these meetings, when there was no official Palestinian water institution and the Palestinian water community was inexperienced compared to the Israeli one.
As in the Truman-PCG initiative, one major process input of IPCRI to negotiations is improved human capital on the Palestinian side. There were several Palestinians who participated in multilateral negotiations, having acquired data, skills, and new knowledge and having built professional relations with Israeli water experts through IPCRI initiatives. One of the Palestinian ex-officials, who was a member of the IPCRI initiatives and the multilateral negotiations suggested: 'People who attended the multilateral meetings were people we talked with when we were writing the [report for IPCRI] .... I think the success of [the multilaterals] started with these Track Two meetings.'

During the Netanyahu period, IPCRI made some input into the policymaking process. IPCRI members had close contact with water policymakers and good relations with the new Israeli Water Commissioner Meir Ben Meir. Their activities during this period were mostly limited to troubleshooting of the day-to-day problems on water, since there were no bilateral negotiations on the issue. It was during this time that they organized an intervention between the senior water officials of both sides to address the daily problems with the help of some Israeli and Palestinian parliamentarians. IPCRI served as an intermediary channel when the official track was not moving, especially on practical matters. Thus, the input of the IPCRI initiatives in the negotiations in the 1990s can be considered as more to the process rather than the outcome.

\section{Comparative Lessons from the Cases}

The outcomes and effects of Track Two initiatives examined contributed to the process of negotiations and institution-building more successfully than the outcome of negotiations in both water and Jerusalem cases. There was transfer to the outcome in only one water initiative, while in all others there 
were varying degrees of contributions to the negotiation and policymaking process.

The most general conclusion that strikes one from the comparative study is that for successful contribution to outcome, an effective transfer strategy (i.e. symmetrical transfer of people and ideas, besides contacts and communication with the negotiators) has to be accompanied with openness to outside information in the negotiation team, and parallel political preferences in the leadership with the ideas promoted by Track Two. Keeping these conditions, or constraints, in mind will be useful both for practitioners in designing their initiatives and researchers in evaluating contributions to outcome. In the case of Truman-PCG input to the Oslo II negotiations, all these three conditions were present. For Jerusalem, in the post-Camp David period there was symmetrical transfer from Track Two in addition to an increasing openness to information on the side of the negotiation team that increased the likelihood of transfer to outcome. Yet, political willingness in the leadership was debatable. On other occasions, such as the preparatory period for Camp David, during Camp David, and for the JWC, few if any of these conditions were met.

Apart from these three conditions affecting transfer to outcome, the comparative study highlights a number of important regularities across the cases. The first one is that even when transfer to outcome is not observed, these initiatives have made a contribution to the process of negotiations that may facilitate a better agreement when the conditions for transfer to outcome are met. Thus, success of Track Two diplomacy should not be defined simply based on contributions to outcome, but should also encompass the contributions to the process. By observing the contributions to the process, one can also capture the important but more subtle and indirect inputs made by these initiatives (other than specific ideas and proposals formulated in the initiatives), such as the transfer of skills, data, and insights to negotiations and institutions. For example, one very significant outcome of both water and Jerusalem initiatives was learning obtained by especially the Palestinian participants concerning new skills, data, knowledge, and, later on, the use of these skills and knowledge in negotiations, which all fed into the process. Table I summarizes all of the learning outcomes reported by the participants of the Track Two initiatives in terms of percentages. The three learning outcomes contributing to the process of negotiation and policymaking are discussed in more detail in the following paragraphs.

As seen, all Track Two initiatives served as important venues for the Palestinians to acquire data and improve their technical,

Table I. Transfer Effects and Outcomes*

\begin{tabular}{lllllll}
\hline Themes & \multicolumn{5}{c}{$\begin{array}{c}\text { Number of workshop participants (\%) } \\
\end{array}$} & \multicolumn{5}{c}{ N (Water = 13, Jerusalem = 27) } \\
\cline { 2 - 7 } & \multicolumn{1}{c}{ I-W } & $P-W$ & $A-W$ & $I-J$ & $P-J$ & $A-J$ \\
\hline New learning & 83.33 & 85.7 & 84.61 & 87.5 & 100 & 92.59 \\
a. Data and skills & 33.3 & 85.71 & 61.53 & 31.25 & 63.63 & 44.44 \\
b. New concepts, insights & 83.33 & 71.4 & 76.92 & 62.5 & 81.81 & 70.37 \\
c. Learning about the other side & 66.6 & 71.4 & 69.23 & 68.75 & 81.81 & 74.07 \\
\hline
\end{tabular}

$\mathrm{I}=$ Israeli participants, $\mathrm{P}=$ Palestinian participants, $\mathrm{A}=$ all participants, $\mathrm{W}=$ water initiatives, $\mathrm{J}=$ Jerusalem initiatives.

* Since the number of participants is small, the percentages should be read as tendencies rather than as precise statistical indicators. 
professional, and negotiation skills. Overall, Table I indicates that about $85 \%$ of the Palestinian participants in water initiatives and about $60 \%$ of Palestinians in Jerusalem workshops reported learning of skills and data. Such learning of skills was transferred to negotiations when these people participated in the negotiations. Examples of this kind of learning and its contribution to negotiations can be seen in the statements of two participants:

We [Palestinian participants] considered these kinds of meetings as an opportunity to exchange information and data. Israelis have more knowledge and experience in these areas. That was an opportunity for us to receive that data because there was no official exchange that we could get that data from.

and

These [Track Two projects on water] were to us areas where we could draw a lot of benefit from the Israeli experience and build the scientific foundation for future Palestinian economic development .... Often, what happened was [these meetings] also developed a lot of expertise in the field of negotiations. Most of the participants, like [name of a Palestinian from the initiative who participated in the official negotiations], did not have expertise in negotiating before. In time, [he] developed these skills and expertise through these projects and workshops.

Although this is not a direct contribution to the outcome of negotiations, through acquisition of skills and data, Palestinian participants, especially those who continued to the official negotiations were able to interact with Israelis on a more equal footing during the negotiations and not surprisingly valued this learning. In this sense, learning of skills and data in the Track Two initiatives empowered the Palestinians by helping them to close the gap between the two sides in terms of capabilities and skills as well as building the capacity of the newly founded Palestinian public and civil society institutions.

Another more subtle, yet important, contribution to the negotiations concerned the transfer of new concepts and insights (Table I) which can only be captured by looking at the process again. Several of the insights gathered from the Track Two initiatives that could be considered as strategic information for the negotiators contributed to the process of negotiations and policymaking. Such knowledge and insights could especially be relevant for the policymakers and negotiators because they included new information on what is feasible in the negotiations or in the joint analysis of the conflict. They were offered by the participants in all water and Jerusalem initiatives examined, but in two occasions - one concerning water, the other Jerusalem - their direct contribution to the process was observed. In the Jerusalem case, a proposal was brought up during the negotiations by the US mediation team to divide the Jerusalem issue into three components (municipal, political, and religious) and to start negotiating with the functional and easier issues. The idea of breaking the sovereignty concept into three was suggested in several Track Two projects and was specifically formulated in an ECF-ASS Track Two initiative by an Israeli-Palestinian team, as an innovative and practical way of addressing the sovereignty question (Cingoli, 2001: 13). As indicated by Dennis Ross, the ideas he used in his initial proposal at Camp David were what he found useful in Track Two meetings:

The very concept that we came up with; to think about it from a conceptual standpoint in three ways as a bureaucratic city that had a function, as a religious city that had certain needs, and as a political city where there has to be sovereignty, some of the disaggregating came, not in a very obvious way, from what [Track Two groups] had discussed, but it informed our thinking. It gave us a handle on how to try to develop an approach. ${ }^{9}$

Similarly, in the water case some of the Israeli water policymakers interviewed

\footnotetext{
${ }^{9}$ Interview with Dennis Ross, Washington, DC, 2003.
} 
suggested that with the help of the Track Two initiatives, their understanding of Palestinian water rights as well as the negotiation flexibility of the Palestinians on this issue became clearer. The joint learning experience the workshop participants went through helped them generate new concepts and insights. This type of learning contributed to the formation of a knowledge-based expert community across conflict lines, whose members acquired similar issue-specific knowledge, a common professional language, and a common frame of reference regarding the conflict.

These qualities make this 'across-theconflict-lines' knowledge-based community a human resource that can be drawn upon when needed. For instance, as a result of the Truman-PCG initiative, Israeli and Palestinian water professionals together generated new knowledge and insights about joint management of shared underground water resources that did not exist before. Likewise, in the IPCRI initiatives, participants jointly created knowledge on water as articulated by an interviewee who later on assumed a role in the Palestinian Water Authority:

The big thing about the project was - now what everyone quotes it for - the minimum water requirement. We were the first ones who came up with minimum water requirement for domestic use as being equitable between Israelis and Palestinians .... People still tell me that for those days it was a breakthrough.... It was minimalist work, but it was the first of its kind.

And on Jerusalem, one participant of the JI-IPCC initiative who attended joint field trips noted:

[Field trips to other cities] opened our minds to new possibilities which we otherwise would not have thought of. For instance, the Swedes took us to a city on the Finnish-Swedish border which decided to unite despite the fact that it belonged to two different countries .... or cities that are designated for mixed ethnic activities.
In addition to these direct and confirmed contributions, more indirect contributions to the negotiations are possible as well, such as how the publication of the models and ideas publicly helped create a discourse and spread the legitimacy of some ideas and break taboos. However, unlike the direct and observable contributions to the process which were confirmed by the negotiators interviewed, such indirect contributions were not traced systematically during this research.

As a final contribution to the process in terms of learning, the participants were able to learn about the other side (Table I) allowing more complex thinking about the other's society and about the sources and dynamics of the conflict. This theme came up regularly from both sides in the interviews, often intertwined with learning of new insights and improvements in relations.

The second major lesson drawn from the comparison of two cases is that the transfer process is more complicated than thought by early practitioners of Track Two. When one engages in a comparative assessment, one also finds important similarities in this complex process, even if cases that are compared belong to two issue areas that seem very different, like water and Jerusalem. In addition to the similarities in outcomes and effects of Track Two workshops as summarized in Table I, another commonality can be found in the strategies and tactics used for transfer.

There were mainly four transfer mechanisms used in both water and Jerusalem initiatives. These were: (1) exporting key influential participants from the Track Two initiatives to negotiations and policymaking institutions, (2) contacts and consultations with decisionmakers and/or official mediators, (3) serving as advisers to policymakers or negotiation teams, and (4) creating, publicizing, and sending artifacts comprised of ideas, maps, and policy recommendations for decisionmakers' attention. 
The mechanisms used by Track Two organizers to transfer ideas and insights in the upwards direction were effective in varying degrees. Of these tactics, contacting the official mediators (US peace team) and exporting key people to the negotiations provided the most direct access to the process and the likelihood of direct input into the negotiations. In this sense, holding Track Two initiatives with influential people was not an adequate strategy by itself, but rather needed to be accompanied by additional actions such as visiting official mediators and convincing them, or working closely with particular official negotiators and lobbying to export people from Track Two to negotiations. Furthermore, simply including key people in Track Two meetings was not adequate because of the asymmetric transfer of people or asymmetric transfer of ideas to the upwards level.

In all of the initiatives, exporting participants to negotiations and policymaking circles occurred and was an important strategy to make an impact. Thus, as was suggested by Fisher (1997), Kelman (1995), and Mitchell (1981, 1993), all initiatives included key influential people that were or could potentially make a direct contribution at the policymaking level and were successful in establishing a direct link between the Track Two and the negotiations. Sometimes, these people were selected for the Track Two project for their already existing influential role in the negotiations and policymaking circles (for example, the Truman-PCG initiative picked influential Palestinian and Israeli water experts who were involved either with negotiations or policymaking), while at other times, the initiatives encouraged and sometimes lobbied for certain participants to take an active role in the negotiations even though initially they were not influential or part of the negotiations (e.g. the ECF-ASS initiative that managed to get one of their staff into the Camp
David negotiations as an assistant to the Chief Negotiator).

This strategy of exporting ideas and insights via influential people inevitably required a careful selection of participants for the initiatives. For this reason, in all of the initiatives the groups were mixed, including both academics/technical experts and politically connected and influential people. The strategy was successfully implemented in all initiatives even though these exported members' contributions usually remained limited to making an input to the process, rather than to the outcome.

The second major transfer strategy was establishing contacts with decisionmakers and/or official mediators. This was used in both water and Jerusalem cases. Compared to the previous strategy, this one is more indirect and is based on influencing the thinking of decisionmakers and negotiators. Contacts with decisionmakers and negotiators were sometimes initiated by the participants of the Track Two project and at other times by the third party and the organizer of the initiative. Also, during these contacts, ideas and proposals were sometimes introduced by one of the sides and at other times by both sides. Anecdotal experiences of some organizers suggest that they were more successful in convincing people when contacts were carried out jointly and ideas were introduced to key policymakers by both sides. This strategy was often used in combination with sending artifacts and the strategy of advising politicians and negotiators.

A third strategy used was the Track Two participants serving as advisers to politicians or negotiators without necessarily participating in the negotiations or serving in the policymaking institutions. This strategy was used on and off by all initiatives, but it became systematic especially in the Jerusalem case. For example, in the ECF-ASS initiative, a month before the Camp David Summit, the 
Jerusalem Task Force was created at Orient House to develop strategies for final status talks based on the ASS work with the ECF and to advise Palestinian negotiators. While the ECF worked closely with the senior negotiator, Gilead Sher, JI people advised Oded Eran, head of Israel's peace directorate.

A final and less direct mechanism used was the sending and publicizing of written artifacts. All four of the initiatives produced various written artifacts and sent them to decisionmakers, policymakers, negotiators, and sometimes to legislators. Just as involving influential people in the workshops alone was insufficient, interviewee anecdotes suggest that the sending of artifacts, by itself, too, was not adequate to make a contribution to the negotiations. Additional efforts, such as finding gatekeepers in the institutions or accompanying the sending of artifacts with direct contacts, are necessary to increase their effectiveness.

Another important lesson drawn from the comparative assessment is concerned with the barriers during the implementation of the transfer strategies. As discussed so far, often the exporting of participants to policymaking institutions or to negotiations and the transfer of ideas to the process of negotiations occurred asymmetrically, meaning that the transfer of participants or ideas took place either from the Palestinian or from the Israeli side, but usually not from both. Thus, the effects and outcomes of the Track Two initiatives did not necessarily transfer reciprocally.

In the case of asymmetrical exporting of people to the policymaking institutions and negotiations, these people usually had to interact with counterparts that did not necessarily go through a similar experience. This was found to be disappointing and frustrating for people whose perceptions of the other side and the conflict were transformed in the workshops. Examples of such frustration and the negative effects on the negotiations were mentioned (and are narrated in this article in the relevant sections) especially in the cases of the JWC concerning the Truman-PCG initiative and the exclusion of Faisal Husseini from the negotiations concerning Jerusalem. An important finding of this study is that when transfer is asymmetrical, its effectiveness is greatly hampered.

Although the asymmetrical exporting of people had adverse effects, ideas and proposals still found their way to the process even when they were asymmetrical, and they were still considered in the negotiations, either with the help of one of the parties or with the help of the official third party. However, when people were not transferred to the negotiations symmetrically and when only one side was open to outside information, the likelihood of a contribution to the outcome by exporting ideas only is still low.

In sum, a comparative look into the contributions of these initiatives to the process of negotiations highlights important regularities in the types of learning acquired and used by the participants, the strategies used to transfer effects and outcomes, and the barriers to effectiveness created by asymmetric transfer of people and ideas.

\section{Conclusion and Directions for Future Research}

The findings reported in this study are certainly limited to the context of the IsraeliPalestinian conflict. But it is a step forward in showing that it is possible to systematically evaluate the Track Two efforts. It was found that even among two issues that seem to be very different (water and Jerusalem), there are remarkable similarities in terms of the process of transfer: the transfer effects and outcomes of the initiatives and the transfer strategies used. Moreover, three key conditions appear to affect the successful transfer to outcome of the negotiations in both water and Jerusalem cases. Research building on this and focusing on the process of Track Two in other conflict contexts will broaden 
our understanding and help the building of theory in this area.

The findings reported in this article suggest that the transfer of effects and outcomes, employing primarily the strategy of working with influential people and exporting them to negotiations and policymaking institutions, was achieved more successfully in impacting the process of negotiations rather than the outcome. Scholars and donors focused primarily on the impact of Track Two on outcome especially by looking at whether ideas have been incorporated into the negotiated agreements or not. Such narrow focus misses the other important contributions of Track Two to the process, such as the contribution of Track Two to the improvement of human capital, which is valuable for negotiations rather indirectly.

Another key point is that the asymmetrical transfer of people, as well as the asymmetrical transfer of ideas to some extent, from Track Two initiatives to negotiations and policymaking positions is a barrier to effectiveness. Such asymmetrical transfer also indicates that Fisher's proposition: 'the closer the participants are to the decisionmakers, the more likely the transfer to official level' is not sufficient as a condition but needs to be qualified. Despite the fact that almost all of the initiatives involved participants who had direct access to the negotiations and policy institutions, closeness and direct connections are not likely to impact the outcome when it is asymmetrical. Thus, closeness to decisionmakers is not adequate to account for transfer to Track One, and the process is much more complex, being contingent upon additional factors.

While this research took a step in the direction of assessing transfer from Track Two initiatives based on participants' and policymakers'/negotiators' self-assessment, much remains to be done in this area. Future research needs to trace what kind of transfer effects and outcomes occur and through what types of strategies when transfer of people is accomplished symmetrically, and whether there are any successful cases of transfer to outcome when there is lack of political willingness.

\section{References}

Assaf, Karen; Nader al-Khatib, Elisha Kally \& Hilel Shuval, 1993. A Proposal for the Development of a Regional Water Master Plan. Jerusalem: IPCRI.

Cingoli, Janiki, 2001. Israelis, Palestinians Coexisting in Jerusalem. Milan: Italian Center for Peace in the Middle East.

Cuhadar, Esra, 2004. Evaluating Track Two Diplomacy in Pre-Negotiation. PhD dissertation, Syracuse University.

d'Estree, Tamra Pearson; Larissa Fast, Joshua Weiss \& Monica Jakobsen, 2001. 'Changing the Debate about Success in Conflict Resolution Efforts', Negotiation Journal 17(2): 101-113.

Feitelson, Eran \& Marwan Haddad, 1995. Joint Management of Shared Aquifers Final Report. Jerusalem: Harry Truman Institute for the Advancement of Peace and the Palestine Consultancy Group.

Feitelson, Eran \& Marwan Haddad, eds, 2000. Management of Shared Groundwater Resources. Boston, MA: Kluwer.

Fisher, Ronald, 1997. Interactive Conflict Resolution. Syracuse, NY: Syracuse University Press.

Fisher, Ronald, 2005. 'Analyzing Successful Transfer Effects in Interactive Conflict Resolution', in Ronald Fisher, ed., Paving the Way. Lanham, MD: Lexington (1-17).

George, Alexander \& Andrew Bennett, 2005. Case Studies and Theory Development in the Social Sciences. Cambridge, MA: MIT Press.

Hassassian, Manuel, 2001. 'Final Status Negotiations on Jerusalem: An Inside Look', paper presented at PASSIA, Jerusalem, 13 March.

Jerusalem Institute for Israel Studies, 2002. Five Years and Beyond: Progress Report of the Jerusalem Institute for Israel Studies 1997-2002. Jerusalem: Jerusalem Institute for Israel Studies.

Kelman, Herbert, 1995. 'Contributions of an Unofficial Conflict Resolution Effort to the Israeli-Palestinian Breakthrough', Negotiation Journal 11(1): 19-28. 
Klein, Menachem, 2003. The Jerusalem Problem. Gainesville, FL: University Press of Florida.

Knesset Report, 2002. 'Parliamentary Committee of Inquiry on the Israeli Water Sector'. Jerusalem.

Lederach, J. Paul, 1997. Building Peace: Sustainable Reconciliation in Divided Societies. Washington, DC: USIP Press.

Lein, Yehezkel, 2000. Thirsty for a Solution: The Water Crisis in the Occupied Territories and its Resolution in the Final Status Agreement. Jerusalem: B'Tselem.

Malhotra, Deepak \& S. Liyanage, 2005. 'LongTerm Effects of Peace Workshops in Protracted Conflicts', Journal of Conflict Resolution 49(6): 908-924.

Malley, Rob \& Hussein Agha, 2001. 'Camp David: The Tragedy of Errors', New York Review of Books, 9 August.

Maoz, Ifat, 2000. 'An Experiment in Peace: Reconciliation-Aimed Workshops of JewishIsraeli and Palestinian Youth', Journal of Peace Research 37(6): 721-736.

Mitchell, Christopher, 1981. Peacemaking and the Consultant's Role. Westmead: Gower.

Mitchell, Christopher, 1993. 'Problem Solving Exercises and Theories of Conflict Resolution', in Dennis Sandole \& Hugo van de Merwe, eds, Conflict Resolution: Theory and Practice. Manchester: Manchester University Press (78-94).
Montville, Joseph, 1995. 'The Arrow and the Olive Branch: A Case for Track Two Diplomacy', in John W. McDonald \& Diane Bendahmane, eds, Conflict Resolution: Track Two Diplomacy. Washington, DC: IMTD (7-25).

Ohanyan, Anna \& John Lewis, 2005. 'Politics of Peace-Building: Critical Evaluation of Interethnic Contact and Peace Education in Georgian-Abkhaz Peace Camp 1998-2002', Peace and Change 30(1): 57-84.

Rodan, Steve, 1995. 'Divided Waters: Part I and II', Jerusalem Post, 1 September.

Ross, Dennis, 2004. The Missing Peace. New York: Farrar, Strauss and Giroux.

Rouhana, Nadim, 2000. 'Interactive Conflict Resolution: Issues in Theory, Methodology, and Evaluation', in Paul Stern \& Daniel Druckman, eds, International Conflict Resolution after the Cold War. Washington, DC: National Academy Press (294-337).

Rouyer, Alwyn, 2000. Turning Water into Politics. London: Macmillan.

Savir, Uri, 1998. The Process. New York: Vintage.

ESRA CUHADAR, b. 1975, PhD in International Relations (Syracuse University, 2004); Assistant Professor, Bilkent University, Department of Political Science (2006- ). Research interests: evaluation of peace initiatives, mediation, political psychology. 